\title{
Para além da normalização: aspectos discursivos das normas de padronização
}

\author{
Daniella Lopes Dias Ignácio Rodrigues*
}

\begin{abstract}
Resumo
O objetivo deste artigo é refletir sobre as normas de padronização do texto acadêmico-científico sob o viés discursivo tomando como objeto de análise prescrições relativas ao uso de aspas e itálico, do discurso relatado e das marcas de pessoa. Toma-se como corpus orientações de duas editoras - uma de Minas Gerais e outra de São Paulo - e dois manuais de normalização. A tese defendida é a de que a intervenção do revisor de textos vai além do sistema linguístico e das questões normativas.

Palavras-chave: Revisão de Textos. Normalização. Discurso.
\end{abstract}

O texto que aqui apresento é fruto de minha prática como professora da disciplina Metodologia Científica no curso presencial de Revisão de Textos da PUC Minas. Nessa disciplina, tenho tido a oportunidade de refletir, entre outras coisas, sobre os modos de dizer em textos acadêmico-científicos e, por extensão, sobre a natureza das intervenções do revisor de textos dessa mesma natureza.

De início, é preciso deixar claro o que entendo por Revisão Textual, a saber, uma prática discursiva. O que isso significa? Significa que as intervenções de revisão textual envolvem a (re)construção, armazenamento, reprodução e circulação de produtos repletos de sentidos (MEDRADO, 1999), tanto para quem os produz (revisores) como para quem os consome (leitores). Como nos lembra Muniz Jr. (2009, p. 9), a intervenção do revisor de textos, "mesmo quando se reduz a meras correções ortográficas, ou mesmo quando ele não faz nenhuma alteração no texto, tem natureza discursiva".

Assumo, de igual modo, que a formação do revisor na qual acredito prevê um profissional que concebe o texto em toda sua plenitude, isto é, um profissional que é capaz de propor intervenções que vão além do meramente gramatical e/ou normativo.

A grande vantagem dessa formação é que ela possibilita o estudo do texto tanto da perspectiva da sua materialidade linguística como das práticas discursivas nas quais ele circula. Assim, o revisor, mais do que conceber a língua escrita do ponto

* Pontifícia Universidade Católica de Minas Gerais (PUC Minas). 
de vista da norma, pode vincular a dimensão propriamente linguística à dimensão textual-pragmática-discursiva. Tal proposta envolve, do ponto de vista linguístico, focalizar tanto questões relativas à ortografia e à pontuação quanto as vinculadas às escolhas lexicais e à estruturação sintática. No que se refere à dimensão textualpragmática-discursiva, essa formação prioriza, fundamentalmente, as estratégias do dizer em relação às condições de produção do discurso.

Tomar essa perspectiva na formação do revisor "implica a seleção de procedimentos pelos quais os textos sejam considerados como passíveis de receberem múltiplos sentidos, de serem reinterpretados, em função das situações em que vierem a circular" (MATENCIO, 2003, p. 8). Entendo, portanto, que a atividade de intervenção textual vai muito além da ideia de corrigir, padronizar e normalizar (SALGADO, 2013).

No que se refere a essa última ideia (normalizar), parece-me que ela é objeto de uma preocupação maior (tanto por parte de quem produz quanto de alguns revisores) na produção/recepção do texto acadêmico. Talvez haja uma supervalorização do como se diz em detrimento do que se diz (BAKHTIN, 2004). Não estou dizendo que as questões normativas não sejam importantes, muito pelo contrário, acredito que elas são uma das formas de materialização dos valores e das práticas acadêmico-científicas. Mas elas não devem ser a maior inquietação daqueles que produzem textos acadêmicos.

Outro ponto que me parece problemático no que tange a essa questão é que as obras de metodologia científica são pouco adequadas tanto para autores como para revisores de textos se se considera que a normatização de produção de gêneros científicos não contempla as práticas discursivas que os engendram. Ou seja, em detrimento de um aparato puramente técnico são deixadas à sombra orientações que poderiam voltar-se para as questões discursivas das normas acadêmicas de produção textual. Essas obras concebem os gêneros discursivos como estáticos, contrariando as proposições bakhtinianas sobre a estabilidade relativa dos gêneros.

Tendo em vista esse quadro, minha proposta é a de repensar algumas questões relativas à normalização científica sob o viés discursivo. Para isso, começo explicitando o conceito de discurso com o qual trabalho e, em seguida, sugiro um novo olhar para as regras de normalização acadêmica no que se refere ao uso de aspas e itálico, do discurso relatado e das marcas de pessoa. Tomo como corpus orientações de duas editoras - uma de Minas Gerais e outra de São Paulo - e dois manuais de normalização. 


\section{As condições de produção dos textos acadêmico-científicos}

Reconhecer a natureza textual-pragmático-discursiva dos textos é assumir que os gêneros discursivos nos quais eles se materializam "ditam" as estratégias do dizer. Nos gêneros acadêmico-científicos haveria, assim, entre várias outras normas (MUNIZ JR., 2009), três que orientam sua produção: a dos gêneros, a ABNT e o padrão de normalização das instituições nas quais circulam.

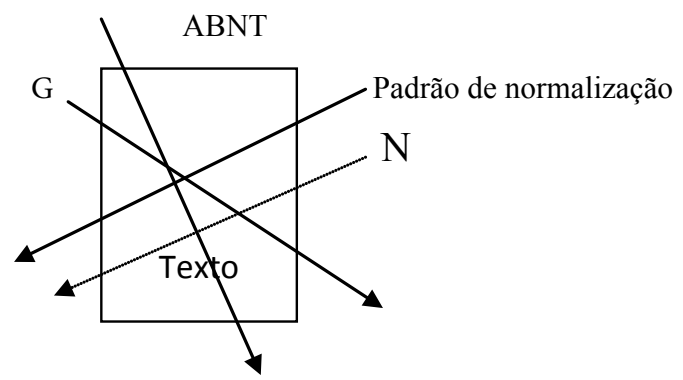

FIGURA: adaptação de Muniz (2009)

Tais normas devem ser vistas sob a ótica argumentativa. Quando usadas, produzem-se sentidos, que são construídos sob certas condições que, em linhas gerais, abarcam:

a) um locutor (aquele que diz, tendo em vista seus papéis sociais e comunicativos);

b) um alocutário (aquele para quem se diz o que se tem a dizer, tendo em vista seus papéis sociais e comunicativos);

c) um referente (o que dizer);

d) uma forma de dizer (as estratégias para se dizer);

e) um contexto em sentido estrito e em sentido lato.

Segundo Cardoso (1999), as condições de produção do discurso não devem ser compreendidas, nesse sentido, apenas como sendo a situação empírica em que se materializa o discurso, mas como sua representação. $O$ interlocutores não devem ser considerados apenas como autores/leitores físicos, mas também como representação de lugares determinados na estrutura social: o lugar do pesquisador, 
do orientador, do arguidor em bancas de defesa de trabalhos acadêmicos, do leitor de textos acadêmicos, etc. As relações entre esse lugares acham-se representadas no discurso por representações que designam os lugares que locutores e a alocutários atribuem a si mesmos e aos outros, a imagem que eles fazem de si e do outro, a imagem que fazem do referente. O locutor (autor e revisor!) pode antecipar as representações do alocutário (leitor) e, de acordo com essa antevisão do imaginário do outro, estabelecer as estratégias do dizer.

Por fim, as condições de "exercício da função enunciativa" (FOUCAULT, 2005, p. 137) do discurso acadêmico englobam um conjunto de regras anônimas, tácitas, historicamente construídas e legitimadas que vão "ditar" o que dizer e como dizer.

\section{Os dados}

Vejamos as orientações que, normalmente, são dadas pelos manuais de normalização para o uso do itálico e das aspas, do discurso relatado e das marcas de pessoa.

Discurso relatado:

\section{a) $\mathbf{O}$ caso da citação de citação}

As prescrições dos documentos consultados sobre o uso da expressão latina apud oferecem a seguinte orientação:

- "Prefira sempre a utilização de textos originais. Evite o uso excessivo das citações de citação $(a p u d)$ ". (PADRÃO PUC MINAS DE NORMALIZAÇÃO, 2010, p. 5).

- "Todo esforço deve ser empreendido para se consultar o documento original". (FRANÇA; VASCONCELLOS, p. 133, 2008).

- "Deve-se, na medida do possível, evitar esse recurso". (RODRIGUES, 2005, p. 21).

Nos excertos de artigos a seguir, há exemplos de citação de citação. ${ }^{1}$ a retextualização no ensino fundamental. SCRIPTA, Belo Horizonte, v. 6, n. 11, p. 171-184, $2^{\circ}$ sem. 
O quadro teórico que assumimos em relação à linguagem centra-se na abordagem enunciativo-discursiva de Bakhtin (1999), cuja ênfase é o processo de interação entre sujeitos sócio-historicamente situados. Dessa forma, a língua é compreendida como uma atividade interativa, social e cognitiva, um sistema aberto, heterogêneo, não um código autônomo estruturado como um sistema abstrato, pré-existente e exterior ao falante, mas ao contrário, ela se constrói a cada processo interlocutivo. Como postula Geraldi (1999 apud COSTA VAL, 2001):

adotar essa concepção não implica postular a indeterminação absoluta da língua, mas sim compreender a sua historicidade: não se trata de um código ou sistema fixo de elementos e regras de combinação, mas de uma sistematização, por natureza plástica e flexível, que, resultante do trabalho linguístico social, historicamente elaborado, acaba por estabelecer regularidades de uso. Desde o nível fonológico até o discursivo, mas prevê, como operação normal, e necessária conforme as circunstâncias, a subversão dessas regularidades na atividade individual de enunciação.

Por que evitar o uso excessivo de citações de citações? As orientações de normalização não nos fornecem muitas justificativas para suas normas, o que não é de se estranhar, pois as proposições prescritivas, geralmente, não carecem de justificativas. Se levarmos em conta as dimensões textual-pragmático-discursivas dos textos, a resposta para essa questão será a seguinte: no exemplo em foco, informar que Geraldi foi lido via Costa Val não é uma estratégia textual condizente com as condições discursivas em que o texto circula, pelo fato de que o primeiro autor é da fácil acesso para os leitores previstos no artigo. A imagem construída pelo discurso citante (o autor do artigo) poderia ser a de um pesquisador que leu pouco sobre seu objeto de estudo e que, por isso, que não fez uma boa pesquisa bibliográfica.

Quem produz texto de natureza acadêmica visa construir a imagem de um pesquisador. Assim, o uso do apud deve ser discutido tendo em vista os efeitos argumentativos que ele provoca e não simplesmente como uma forma a ser evitada. 


\section{b) $\mathbf{O}$ caso da evocação}

O conceito de evocação é cunhado pelos pesquisadores franceses Françoise Boch e Francis Grossmann (2002), que a definem como a alusão que escritores fazem a trabalhos sem pretender resumir seu teor, como ilustra o exemplo a seguir ${ }^{2}$ :

As dificuldades vivenciadas na formação - inicial e continuada - do professor de Português no que diz respeito à leitura e produção de textos que circulam no meio acadêmico e, por extensão, ao modo de funcionamento dos discursos que constróem e constituem o campo dos estudos da linguagem têm sido constantemente objeto de trabalhos voltados à formação e prática de ensino/aprendizagem (cf., dentre outros, ASSIS, MATENCIO e SILVA, 2000; KLEIMAN, SIGNORINI e colaboradores, 2000; KLEIMAN, 2001; MARINHO, 2001).

Não se têm nos manuais consultados orientações sobre o que seja a evocação. Mas existe a prescrição sobre seu uso: "Optamos pelo sistema de chamada autor-data. Exemplo: (SANTOS, 1997)". (PADRÃO PUC MINAS DE NORMALIZAÇÃO, 2010, p. 19).

Ao discutir sobre a autoridade do discurso relatado, Maingueneau (1997) afirma que seu valor reside em cada formação discursiva, já que o sujeito que enuncia a partir de um lugar definido não cita quem deseja, como deseja, mas de acordo com as imposições desse lugar discursivo que regulam as citações. Nesse sentido, mais que ter conhecimento sobre a forma de entrada que as citações devem ter nos textos de cunho acadêmico-científico, deve-se saber o valor das escolhas referencias que se faz.

\section{c) $\mathrm{O}$ caso do discurso indireto}

A norma dada por um dos manuais consultado diz que "a citação indireta ou livre ocorre "quando se reproduzem as ideias, sem transcrever as palavras do autor.

2 MATENCIO, Maria de Lourdes Meirelles. Atividades de (re)textualização em práticas acadêmicas: um estudo do resumo. SCRIPTA, Belo Horizonte, v. 6, n. 11, p. 109-122, $2^{\circ}$ sem. 2002. 
OBS: Para citações livres a indicação da página é opcional”. (PADRÃO PUC MINAS DE NORMALIZAÇÃO, 2010, p. 19).

Consideremos o exemplo ${ }^{3}$ :

Conforme Goldfeld (2002), os conceitos de linguagem, língua, fala e signo linguístico foram primeiramente sistematizados por Saussure (1916).

Se se considera, mais uma vez, o jogo de imagens que é construído em toda situação de interlocução, afirmar que "os conceitos de linguagem, língua, fala e signo linguístico foram primeiramente sistematizados por Saussure (1916)", à luz de outro autor, no caso em estudo Goldfeld (2002) não é muito estratégico discursivamente, já que tal informação é velha conhecida dos leitores conjecturados no artigo.

\section{Itálico e aspas}

Quanto ao uso do itálico e das aspas, consultei orientações dadas por duas editoras, uma em Minas Gerais e outra em São Paulo. A de São Paulo prescreve ${ }^{4}$ :

- "8. Destaques:

Para destacar e chamar a atenção para palavras ou trechos no corpo do texto, pode-se escrevê-las em itálico, sem sublinhado e sem negrito.

Observação: É prática corrente e correta o uso de “ " para realçar alguma expressão em meio ao texto, apenas deve-se tomar cuidado para que isso não dê margem a confusões com citações de outros autores".

A de Minas Gerais diz

- "Os itálicos devem ser usados apenas, no corpo do texto, para palavras em língua estrangeira, reservando-se as aspas para qualquer outro destaque".

O ponto de vista discursivo de Authier-Revuz (1998) sobre o uso das aspas e do itálico demonstra que essas marcas tipográficas são formas de heterogeneidade mostrada, que podem ser recuperadas somente no nível enunciativo e não no nível

3 Exemplo coletado em trabalho de pós-graduação.

4 EDITORA MERCADO DE LETRAS. Critérios para a elaboração de originais. São Paulo: Mercado de Letras, 2015.

5 EDITORA PUC MINAS. Normas para os colaboradores da revista Scripta. Belo Horizonte: Scripta, 2009. 
do enunciado.

Assim, como intervir nessas marcas sem provocar efeitos de sentido? Quando os autores as usam, eles objetivam sinalizar outras vozes, consonantes ou dissonantes, que são reconstruídas na atividade de leitura. Padronizar a utilização dessas marcas, a meu ver, é muito complexo para ser objeto da arbitrariedade normativa. Vejamos um exemplo ${ }^{6}$ em que o autor utiliza as aspas para enfatizar a qual discurso essa palavra pertence:

Observamos que, com a repetição da atividade em circunstâncias pouco alteradas, essa estrutura vai se estabilizando até atingir uma forma "relativamente estável".

Nesse caso, o uso das aspas atende à prescrição da editora de Minas Gerais. Mas, no caso a seguir, o revisor da editora de São Paulo teria problemas se trocasse as aspas por itálico:

No caso em estudo, o "poder" do professor diante dos alunos parece inquestionável.

Pode ser uma questão de leitura, mas não vejo que o itálico teria o mesmo efeito de sentido pretendido pelo autor do trecho acima. É pertinente retomar aqui os dizeres de Authier-Revuz (2004, p. 219), que considera as aspas como uma "arquiforma”, ao fazer o seguinte comentário acerca das aspas: "O distanciamento pontual das aspas requer, supõe que, de modo global, uma atitude metalinguística de desdobramento do locutor ocorre em uma fala acompanhada, duplicada, por um comentário crítico, no próprio curso de sua produção". Relacionando esses dizeres com o fragmento anterior, observo que as aspas revelam que o sujeito-enunciador faz uma espécie de comentário crítico do próprio uso de suas palavras. Ainda, conforme a autora, "essa atitude manifesta uma aptidão: ela coloca o locutor em posição de juiz e dono das palavras, capaz de recuar, de emitir um julgamento sobre as palavras no momento em que as utiliza". (AUTHIER-REVUZ, 2004, p. 219).

Enfim, as aspas e o itálico exigem o reconhecimento e a interpretação do leitor da presença de outras vozes e, por isso, a meu ver, não são facilmente intercambiáveis. Ademais, um dos fatores que determinam as escolhas linguísticas ou estruturais é o leitor pretendido.

6 Exemplo coletado em trabalho de pós-graduação. 


\section{Pessoas do discurso}

Por fim, mas não menos importante, (peço licença para usar a frase feita!) temos o caso do tabu em torno do uso da primeira pessoa do singular em textos que circulam na esfera acadêmica.

"O texto científico deve ser redigido de forma impessoal (observa-se, observou-se, observaram-se, observam-se, etc.)" (PADRÃO PUC MINAS DE NORMALIZAÇÃO, 2010, p. 5), orienta o manual consultado. Há, também, acredito, um acordo tácito, construído pelas normas do métier, interiorizado, de que se deve padronizar o uso das pessoas do discurso ao longo do texto: caso o escritor opte pela primeira pessoa do singular, que a use ao longo de todo o texto; caso prefira pela primeira do plural, que a utilize até o fim do trabalho.

Ora, as três pessoas (primeira do singular e do plural e terceira do singular) podem ser usadas nos textos concomitantemente, pois elas visam a efeitos retóricos distintos. Vejamos: ${ }^{7}$

Sabemos que o processo de formação contínua de professores é visto, há algum tempo, não como um processo de transmissão de conhecimentos científicos efetivado pelo formador-pesquisador, mas como um local de reflexão sobre as práticas dos professores, sobre suas representações sobre o ensino/ aprendizagem de uma determinada disciplina, sobre os objetivos que visam alcançar, sobre os conteúdos que buscam ensinar; enfim, sobre a coerência interna de suas ações educacionais (cf., dentre outros, Magalhães, 1999; Liberalli, 1999).

Buscando avançar nessa perspectiva, meu objetivo mais amplo é o de defender a tese de que a formação contínua de professores pode e deve ser vista como um trabalho conjunto de construção de conhecimentos científicos pertinentes à disciplina envolvida e à transposição didática e não como simples aplicação de conhecimentos já desenvolvidos na área.

O texto focaliza, inicialmente, os pressupostos teóricos, didáticos e metodológicos que guiaram o trabalho. [...]

7 MACHADO, Anna Rachel. (2004). A formação de professores como locus de construção de conhecimentos científicos. Texto cedido pela autora aos alunos do Programa de Pós-graduação em Linguística Aplicada da PUC São Paulo. 
Parece-me que o objetivo do autor do artigo em análise é marcar, no primeiro parágrafo, com o uso da $1^{\text {a }}$ pessoa do plural, o pertencimento a uma comunidade discursiva (sabemos, nós, pesquisadores da área de linguística aplicada). No segundo parágrafo, o uso da $1^{a}$ pessoa do singular tem o efeito de aproximação do leitor, em que o autor assume claramente sua autoria - meu objetivo é. E a impessoalidade dos sintagmas "O texto focaliza" pode ser vista com o objetivo retórico de delinear a organização tópica (macroestrutural) do artigo. Portanto, é perfeitamente possível, a meu ver, a coexistência das três formas em textos acadêmicos. Além disso, não faz mais sentido, depois de tantas pesquisas sobre o funcionamento da linguagem, afirmar que o uso da primeira pessoa deve ser evitado em trabalhos acadêmicos e é somente aconselhável em pesquisas qualitativas ou estudos de caso.

\section{Palavras finais}

Para encerrar, postulo aqui uma formação do revisor de textos que contemple as práticas discursivas em que os textos são engendrados. Nego uma formação que conceba a língua como um produto acabado e como sinônimo de grámatica normativa.

Com os dados que apresentei, talvez tenha possibilitado a leitura de que o revisor de textos deva conhecer o quadro teórico com os quais os autores da escrita científica trabalham para poder operar com as normas acadêmicas. O que afirmo é que um revisor deve conhecer o funcionamento do discurso em que o texto revisado será consumido, o que significa conhecer o funcionamento dos gêneros no interior de suas práticas. "Os tipos e os graus de intervenção são mais ou menos autorizados de acordo com o gênero ao qual o texto parece pertencer", como afirma Muniz Jr. (2009, p. 13). Se há um uso exacerbado, por exemplo, de citação de citação em um texto acadêmico, isso pode ser observado pelo revisor se ele tiver uma formação que o faz ver o texto para além do sistema linguístico e das questões normativas.

Penso também que precisamos ter no mercado editorial manuais que ofereçam recomendações redacionais de natureza discursiva, e não somente normativa, aos produtores de textos científicos e, por extensão, aos revisores. 


\begin{abstract}
The goal of this article is to reflect about the standardization rules for academic-scientific texts under a discoursive point of view, taking as object the analysis of prescriptions regarding the use of quotation marks and italic, of reported discourse and of the linguistic person marks. The corpora taken are the guidelines of two editors - one from Minas Gerais and another from São Paulo - and two normalization manuals. The thesis defended is that the intervention of the text proofreader goes beyond the linguistic system and normative matters.
\end{abstract}

Keywords: Text Proofreading. Normalization. Discourse.

\title{
Referências
}

AUTHIER-REVUZ, Jacqueline . Palavras incertas: as não-coincidências do dizer. Tradução de Claudia R. Castellanos Pfeiffer, et al. Revisão técnica da tradução Eni Pulccinelli Orlandi Campinas: Ed. da UNICAMP. 1998.

AUTHIER-REVUZ, Jacqueline. Heterogeneidade mostrada e heterogeneidade constitutiva: elementos para uma abordagem do outro no discurso. In: Entre a transparência e a opacidade: um estudo enunciativo do sentido. Apresentação Marlene Teixeira; revisão técnica da tradução de Leci Borges Barbisan e Valdir do Nascimento Flores. Porto Alegre: EDIPUCRS, 2004.

BAKHTIN, Mikhail. Marxismo e Filosofia de Linguagem. São Paulo: Hucitec, 2004.

BOCH, Françoise; GROSSMANN, Francis. Referir-se ao discurso do outro: alguns elementos de comparação entre especialistas e principiantes. Belo Horizonte: SCRIPTA, v. $6, \mathrm{n}^{\circ} 11,2^{\circ}$ sem. de 2002.

CARDOSO, Silvia Helena B. Discurso e ensino. Belo Horizonte: Autêntica, 1999. FOUCAULT, Michel. A arqueologia do Saber. Rio de Janeiro: Forense Universitária, 2005.

FRANÇA, Júnia L.; VASCONCELLOS, de Ana Cristina. Manual de normalização de publicações técnico-científicas. 8 ed. Belo Horizonte: Ed. UFMG, 2008.

MAINGUENEAU, Dominique. Novas tendências em Análise do Discurso. 3 ed. São Paulo: Pontes, 1997.

MATENCIO, Maria de Lourdes. M. Alfabetização e educação ao longo da vida: a questão conceitual. III Telecongresso Internacional de Educação de Jovens e Adultos. Belo Horizonte: SESI Minas, 2003. 
MEDRADO, Benedito. Textos em cena: a mídia como prática discursiva. In: SPINK, Mary, Jane. Práticas discursivas e produção de sentidos no cotidiano: aproximações teóricas e metodológicas. São Paulo: Cortez, 1999.

MUNIZ Jr, José de Souza. A intervenção textual como atividade discursiva: considerações sobre o laço social da linguagem no trabalho de edição, preparação e revisão de textos. (2009). Disponível em: http://www.intercom.org.br/papers/ nacionais/2009/resumos/R4-1079-1.pdf . Acesso em: mar. 2015.

PONTIFÍCIA UNIVERSIDADE CATÓLICA DE MINAS GERAIS. Pró-reitora de Graduação. Sistema de Bibliotecas. Padrão PUC Minas de normalização: normas da ABNT para apresentação de artigos de periódicos científicos. Belo Horizonte: PUC Minas, 2010. Disponível em http://www.pucminas.br/ documentos/normalizacao artigos.pdf. Acesso em: out. 2015.

RODRIGUES, André Figueiredo. Como elaborar citações e notas de rodapé. 3 ed. São Paulo: Associação Editorial Humanitas, 2005.

SALGADO, Luciana Salazar. Ritos genéticos editoriais: uma abordagem discursiva da edição de textos. Rev. Inst. Estud. Bras., São Paulo , n. 57, Dec. 2013 . Disponível em: $<$ http://www.scielo.br/scielo.php?script=sci_arttext\&pid=S002038742013000200011\&lng=en\&nrm=iso >. Acesso em: 19 mar. 2015.

Submetido em: 05 de agosto de 2015. Aceito para publicação em: 27 de outubro de 2015. 